\title{
EL TRATAMIENTO HEGELIANO DE LA INTELECCIÓN COMO REFUTACIÓN DE LA TEORÍA DEL CONOCIMIENTO NOMINALISTA
}

\author{
HEGEL'S TREATMENT OF INTELLECTION AS A REFUTATION OF \\ THE NOMINALIST THEORY OF KNOWLEDGE
}

\author{
Juan José Padial ${ }^{1}$ \\ Universidad de Málaga (España)
}

Recibido: 29-09-2014

Aceptado: 27-10-2014

\begin{abstract}
Resumen: La concepción hegeliana de la intelección y del intelecto (i.) asume el nominalismo y no es entendible sin sus posiciones acerca de la facticidad y del ser empírico. (ii.) Da razón de la parcialidad y unilateralidad del punto de vista nominalista. (iii.) Intenta autofundamentar la verdad en el modo de afirmar que el intelecto se conoce a sí mismo como la totalidad de las determinaciones pensables, como la totalidad de lo inteligible. Al cumplir estos objetivos, se puede advertir (iv.) lo infundado de las apreciaciones de Peirce sobre el presunto nominalismo de Hegel y (v.) completar y dar razón del tratamiento ontológico realizado por Stern en su réplica a Peirce.
\end{abstract}

Palabras-clave: Intelecto, Hegel, Nominalismo, Peirce, R. Stern, L. Polo.

\begin{abstract}
Hegel's grasp of intellection and of intellect (i.) takes on the nominalist one and it is not understandable without Ockam's thesis on facts and empirical being. (ii.) It explains the partiality and one-sidedness of the nominalist point of view. (iii.) It tries to found truth in itself by asserting that the intellect knows itself as the whole of thought determinations, as the totality of what is intelligible. By achieving these aims, one can notice (iv.) a correction to Peirce's thesis on the presumed nominalism of Hegel, and (v.) another strategy, different from the one of Stern, to oppose Peirce's thesis.
\end{abstract}

Key-words: Intellect, Hegel, Nominalism, Peirce, R. Stern, L. Polo.

[1] (jjpadial@uma.es) Es profesor de Filosofía en la Universidad de Málaga. Ha realizado estancias de investigación en la Universidad de Munich, en la Schelling-Kommission de la Academia Bávara de las Ciencias (Munich) y en la Universidad de Glasgow. Es miembro del Grupo de Investigación sobre el Idealismo alemán de la Universidad de Málaga; y de la Sociedad Hispánica de Estudios sobre Hegel y de la Sociedad Hispánica de Antropología Filosófica. Es director del Servicio de Información Bibliográfica para la Filosofía, Secretario del Instituto Filosófico Reinhard Lauth, y del Instituto de Estudios Filosóficos Leonardo Polo. Se ha especializado en el estudio de la antropología filosófica del idealismo alemán. 


\section{El debate pragmatista sobre el presunto nominalismo de Hegel}

El 2 de abril de 1903, Charles Sanders Peirce pronunció la segunda de sus conferencias Harvard, a la que tituló On Phenomenology, y en la que acusó a Royce, y por ende a Hegel, de nominalista:

\footnotetext{
“Toda la filosofía moderna está construida sobre el ockhamismo, por tal cosa entiendo que toda ella es nominalista y que adopta el nominalismo a causa de la navaja de Ockham. Y no hay ninguna forma que haya adoptado la filosofía moderna, en que esto sea más esencialmente verdadero que la filosofía de Hegel.”2
}

Peirce entiende que el principio ockhamista de economía, su célebre navaja, reduce lo real a lo empírico, a lo fáctico,-esse in actu, en un presente reducido al instante, cabría decir- segando de la realidad sus dimensiones potenciales, a las que Peirce se refiere como esse in futuro. Correlativamente la posibilidad se traslada a lo mental, a lo eidético, que puede corresponderse o no con lo empírico. Es decir, lo pensable tiene un valor hipotético y problemático en su referencia a la realidad, pero en cualquier caso es posible. Esta es la postura nominalista en sentido estricto, que problematiza agudamente el valor real de nuestros conocimientos, también de los científicos, y no sólo de los especulativos.

Se trata de una cuestión muy candente, como Robert Stern ha señalado, pues "se relaciona con cuestiones que son centrales en los debates filosóficos contemporáneos que atañen a la naturaleza del realismo, el idealismo y el anti-realismo." 3 La convergencia de los estudios hegelianos y pragmatistas en los últimos años, ha llevado inevitablemente a autores como Stern a encararse con Peirce, pues lo que está en juego para pragmatistas e idealistas es contestar las tesis nominalistas en beneficio del realismo de nuestro conocimiento del mundo: las leyes científicas, los universales, las categorías conceptuales, etc. Por eso, Stern argüirá a Peirce que "él podría haber tratado, con facilidad, a Hegel como un aliado en la lucha con el nominalismo". ${ }^{4}$

Se trata de un debate centrado ante todo en el logos, es decir, en los productos del intelecto, y no en el intelecto mismo, en el noûs. Según Peirce todo depende de dilucidar si las regularidades conocidas y que podemos, por ejemplo, predecir, se dan en la realidad o sólo en la mente. La posición nominalista reside en distinguir tajantemente lo real como singular, de lo mental, que es exclusivamente urdido o fingido por la mente, pero que no tiene correlato real o referencia ninguna. Esta es la arena en la que disputan realistas, idealistas,

[2] Peirce, Ch. S., The Essential Peirce: Selected Philosophical Writings, Indiana University Press, Bloomington, 1992, vol II, pp. 156-57. Citado por Stern, R., "Peirce on Hegel: Nominalist or Realist" en Transanctions of the Charles S. Peirce Society, XLI (1), p. 69.

[3] Stern, R., "Peirce on Hegel: Nominalist or Realist", cit., p. 65.

[4] Ídem.

THÉMATA. Revista de Filosofía, N50 julio-diciembre (2014) pp.: 177-199 doi: 10.12795/themata.2014.i50.08 


\section{El tratamiento hegeliano de la intelección como refutación de la teoria del conocimiento nominalista}

el "verdadero idealismo, es decir el idealismo pragmatista" y los anti-realistas en epistemología y ontología.

El planteamiento del debate por parte de Stern impugna las acusaciones de Peirce acerca de: (i.) que para Hegel sólo tendría sentido la noción de realidad efectiva, como aquella que se corresponde sin residuos con lo lógico-racional. (ii.) Que consecuentemente Hegel prioriza el pensamiento sobre la experiencia, y que el fundamento de nuestro conocimiento universal quedaría confinado en la mente. (iii.) Que no hay lugar en Hegel, por lo tanto, para la "frescura y el hecho bruto" - brute fact- como fundamento del carácter abierto y falible de la investigación científica. Stern responde señalando el lugar que corresponde a lo contingente y lo que existe-inmediatamente-ahí en el sistema hegeliano ${ }^{6}$, y el carácter experienciable de las leyes y conceptos. Es decir, mostrando cómo Hegel amplía el concepto de experiencia. ${ }^{7} \mathrm{Y}$ esto es lo afirmado por el primero de los tres silogismos con que concluye la Enciclopedia de las Ciencias Filosóficas:

\footnotetext{
"Hegel sienta claramente que el papel del espíritu como mediador no es determinar o estructurar la naturaleza a través de la Idea misma, sino meramente reconocer o discernir (erkennen) esta estructura como ya existente en la naturaleza. Pues, como Hegel sentó en el primer silogismo, la naturaleza es "en sí misma la Idea". La tarea del espíritu como mediador es explicitar esta estructura implícita y consiguientemente permitir a la naturaleza mediar entre ella misma y la Lógica."
}

Así pues, la experiencia cognoscitiva se basa en un reconocimiento de la racionalidad de la naturaleza. Racionalidad que, por lo tanto, no es mera coherencia de lo eidético. Esta es la postura nominalista respecto de lo mental. Lo posible, como mental es lo co-posible, lo coherente. Pero hay muchos mundos de co-posibilidades que la mente puede urdir. Si esa racionalidad existe efectivamente es algo que los presupuestos del nominalismo impiden afirmar. La postura hegeliana equivale pues la rehabilitación de la verdad frente a la mera coherencia o corrección de nuestros constructos mentales.

El núcleo de la posición nominalista, según Peirce, radica en la noción de hecho empírico. Una noción que excluye de sí la posibilidad real, la dynamis kata physin aristotélica. El sentido del ser que desea rehabilitar Peirce. El singular es lo que es, en su contingencia, como de hecho es. Así es de facto y excluye de sí cualquier otra posibilidad de ser. Posibilidades que son mentales, hipótesis que formulamos sobre dicho singular. Peirce tiene además razón en negar que para un nominalista el singular pueda fundamentar las posibilidades mentales. Pero entonces, ¿cómo tienen que ver nuestros conceptos con los individuos singulares sobre los que versan? A Peirce le parece que Hegel es un

[5] Peirce, Ch. S., The Essential Peirce..., II, 354. Citado por Stern, R., "Peirce on Hegel..." p. 71.

[6] Stern, R., Op. cit., p. 77.

[7] Ibid., p. 79 y ss.

[8] Stern, R., Hegel, Kant and The Structure of the Object. Routledge, Londres, 1990, p.117.

THÉMATA. Revista de Filosofía, Nº50 julio-diciembre (2014) pp.: 177-199

doi: 10.12795/themata.2014.i50.08 
filósofo postkantiano porque las categorías lógicas son subjetivas, propias del pensamiento, y que esta subjetividad es la legisladora.

La entera discusión de Stern con Peirce se realiza en el terreno de la metafísica especulativa. Pero cabe quizá dar un paso atrás, a una posición de mayor radicalidad si cabe. Y es retrotraer el debate del logos ya constituido a su posibilidad de constitución, es decir, al nous, al intelecto. Esto implicaría abordar la teoría hegeliana de la intelección, y dirimir desde ella la acusación peirciana a Hegel de presunto nominalista. Se trata de una estrategia que no es abordada por Stern, que complementa su enfoque, y que va a ser acometida en estas páginas.

Y esta es la posición desde la que Leonardo Polo aborda la cuestión. Él está de acuerdo con Peirce en que "toda la filosofía moderna está construida sobre el ockhamismo". Esa es la tesis principal acerca de la filosofía moderna en su libro Nominalismo, idealismo, realismo. En él, el idealismo es visto como una reacción frente al nominalismo. Según Polo, "la refutación de Ockham lleva al idealismo. Y, al revés, el idealismo entra en crisis en función de la argumentación nominalista." Por eso, Polo no estaría de acuerdo con la afirmación de Peirce de que Hegel es el exponente por antonomasia del nominalismo. Aunque si estaría de acuerdo en que es imposible concebir el idealismo sin el concurso del nominalismo.

"El idealismo no se entiende sin el nominalismo (tanto el idealismo moderno, cuya primera fase es el racionalismo, y su segunda y última el idealismo alemán, como la reposición que Husserl propone en los inicios del siglo XX). Históricamente, el idealismo ha sido una reacción frente al nominalismo, un modo de salvar la filosofía."10

Veamos cómo la concepción hegeliana de la intelección y del intelecto (i.) asume el nominalismo y no es entendible sin sus posiciones acerca de la facticidad y del ser empírico. (ii.) Da razón de la parcialidad y unilateralidad del punto de vista nominalista. (iii.) Intenta autofundamentar la verdad en el modo de afirmar que el intelecto se conoce a sí mismo como la totalidad de las determinaciones pensables, como la totalidad de lo inteligible. Al cumplir estos objetivos, se logra (iv.) rectificar las apreciaciones de Peirce y (v.) completar y dar razón del tratamiento ontológico realizado por Stern.

\section{Lugar sistemático y real de la inteligencia y el intelecto en la obra hegeliana}

Hegel desarrolla su teoría del intelecto finito y subjetivo en la psicología que culmina su teoría del espíritu subjetivo. La primera sección de la psicología de la Enciclopedia se titula "El espíritu teorético", y es toda ella una teoría de

[9] Polo, L., Nominalismo, idealismo, realismo, Eunsa, Pamplona, 1997, p. 22.

[10] Ibídem, p. 18.

THÉMATA. Revista de Filosofía, Nº50 julio-diciembre (2014) pp.: 177-199 doi: 10.12795/themata.2014.i50.08 
la inteligencia. No en vano, Hegel comienza y termina estos parágrafos hablando de Die Intelligenz. ${ }^{11}$ Esta observación no es meramente erudita. En la Ciencia de la Lógica y en la Fenomenología del espíritu se pueden encontrar numerosas alusiones a la división -central desde Kant- entre entendimiento -Verstand- y razón -Vernunft-. Esta división también es tratada en la "Fenomenología" de la Enciclopedia. La psicología de la Enciclopedia se inaugura prescindiendo de esta distinción. Hegel se sitúa a una distancia desde la que entendimiento y razón no se aprecian como opuestos sino como englobados en la actividad intelectiva. ${ }^{12}$ Pero el hecho de que la psicología no atienda a esta oposición, sino a la que hay entre intelecto y voluntad, o entre espíritu teorético y espíritu práctico, nos proporciona el lugar sistemático y real de la teoría hegeliana sobre el intelecto.

Sistemáticamente Hegel trata del intelecto finito tras haber realizado (i.) una teoría de la inmersión del espíritu en la naturaleza -Antropología-, y (ii.) una teoría de la emergencia de la subjetividad, la conciencia y la autoconciencia -Fenomenología- que culmina en la dilucidación de la intersubjetividad como fundamento de la razón y la racionalidad. El reconocimiento de la racionalidad y universalidad de cualquier autoconciencia hace posible las relaciones entre seres humanos, porque cada uno reconoce libremente en el otro la misma racionalidad que encuentra cabe sí. Así es como la fenomenología de la Enciclopedia culmina con la identidad entre el yo y su alteridad. Es decir con la identidad del nosotros.

Y con esta identidad se inaugura la psicología de la Enciclopedia. La psicología parte de esta identidad, la produce y realiza. Si la fenomenología parte de la oposición sujeto-objeto, la teoría de la inteligencia cancela esta oposición. Y éste es el fenómeno primordial de la inteligencia, el poner la racionalidad de lo encontrado externamente, hacerlo propio, porque dicha racionalidad es idéntica a la de la autoconciencia. La inteligencia es la encargada del desarrollo de este momento tan fundamental como inicial:

"El camino del espíritu es: a) ser espíritu teorético, tener que habérselas con lo racional como determinidad suya inmediata y ponerlo desde ahora como lo suyo; o liberar al saber de la presuposición y con ella de su abstracción y hacer subjetiva la determinidad. En tanto

[11] Hegel, G. W. F., Enzyklopädie der Philosophischen Wissenschaften im Grundrisse (1830), , edición de Wolfgang Bonsiepen y Hans-Christian Lucas con colaboración de Udo Rameil, en Gesammelte Werke, vol. 20, Meiner, Berlin, 1992. Se usa la traducción de Ramón Valls Plana en Alianza editorial, Madrid, 2010. Cuando se modifica la traducción se indica. En adelante se cita como Enz. Enz. §§ 445-468.

[12] Ramón Valls llama la atención sobre que "Intelligenz equivale al intellectus de la tradición latina y recubre por tanto todo lo que en Hegel es el campo del espíritu teorético incluyendo el entendimiento o Verstand. Intelligenz se contrapone y complementa así con Wille (voluntad) la cual recubre a su vez el campo del espíritu práctico. Vernunft no sirve para mencionar lo teorético solo porque también hay que contar con la razón práctica.” Valls, P., nota 777 a Hegel, G.W.F., Enciclopedia de las ciencias filosóficas, Alianza, Madrid, 1997, pp. 487-88.

THÉMATA. Revista de Filosofía, $\mathrm{N}^{\circ} 50$ julio-diciembre (2014) pp.: 177-199

doi: 10.12795/themata.2014.i50.08 
así el saber está determinado como en y para sí dentro de sí, la determinidad está puesta como suya, y [el saber] es así como inteligencia libre-freie Intelligenz ist-."13

Así el movimiento de la inteligencia consiste en transformar lo meramente existente, lo dado y encontrado de forma fáctica - das Seiende- en algo propio y racional -das Seinige-, en hacer suyo lo que aparecía como externo. Esto es lo que estaba implícito en la "Fenomenología del espíritu" de la Enciclopedia, lo que acontece por primera vez merced a las relaciones intersubjetivamente libres. Esta interiorización de lo existente, de lo objetivo, de lo dado o encontrado, de la exterioridad, de lo que aparece como necesario, es el quehacer de la inteligencia. Una tarea en la que radica su vocación, como había mostrado con inusitada fuerza en la Fenomenología del espíritu de Jena:

\footnotetext{
"La razón, que al principio no hace más que barruntarse en la realidad o que solo sabe esta realidad como lo suyo en general, procede en este sentido hasta la toma universal de posesión de la propiedad de que está segura y planta en todas las alturas y en todas las simas el signo de su soberanía. Pero [...] la razón se barrunta todavía como una esencia más profunda [...] y exige que el ser multiforme llegue a ser lo suyo mismo, la realidad de ella [...]. Pero si la razón revuelve todas las entrañas de las cosas y abre todas sus venas para verse brotar por ellas, jamás alcanzará esta dicha, sino que tiene que realizarse en ella misma, para poder luego experimentar su realización.”14
}

Reconocer la racionalidad es un fenómeno esencial para el intelecto, porque se descubre a sí en lo otro -en lo encontrado-. Poner la idealidad de lo que está siendo meramente -das Seiende- es asimilar lo encontrado a la forma del espíritu, hacerlo intelectual y no meramente inteligible. Esta es la actividad de la inteligencia: un idealizar: Ideelsetzung. En esta elaboración de la inteligibilidad, en este poner la idealidad, se descubre que la racionalidad de lo encontrado externamente, es decir, la racionalidad del objeto, es la misma que la que el espíritu descubre de sí, de su subjetividad. Pero se trata de una racionalidad producida por el espíritu, suya e interna.

Para el espíritu descubrirse es su propia vocación. Un espíritu es un ser para el que es esencial saber lo que es, saberse. Y esto comienza a cumplirse merced a la actividad intelectual, a la actividad que reconoce la racionalidad de lo objetivo, y en dicha actividad productiva se reconoce a sí. Por ello, la actividad intelectual viene a ser el primer momento del aparecer del intelecto para sí. El espíritu aparece aquí para sí como es -como intelectual-, y es como aparece - como actividad libre, no determinada externamente, sino que pone la racionalidad de lo que encuentra.

Tennemann, uno de los historiadores de la filosofía que seguía Hegel, había señalado que la importancia de Ockham residía en el descubrimiento de

[13] Enz., § 443.

[14] Fen., FCE, p. 149.

THÉMATA. Revista de Filosofía, Nº50 julio-diciembre (2014) pp.: 177-199 doi: 10.12795/themata.2014.i50.08 


\section{El tratamiento hegeliano de la intelección como refutación de la teoria del conocimiento nominalista}

la subjetividad ${ }^{15}$, pues los universales no son reales, sino fingidos por el espíritu, puestos en el sujeto y por el sujeto como signos que suponen por lo real. En las Lecciones sobre Historia de la Filosofía Hegel cita un pasaje de la octava de las Quaestiones de Ockham, donde Ockham subraya la acción productiva del intelecto, y el carácter libre y subjetivo de las representaciones y conceptos:

"La inteligencia, al percibir una cosa fuera del alma, se forma otra cosa semejante a ella dentro del espíritu, de tal modo que, si estuviese animada por una capacidad productiva, la alumbraría como un artista, como una unidad numérica distinta de la anterior, en un sujeto que es en y para sí. Y si a alguien no le agrada que llamemos a esta representación hecha, podríamos decir que la representación y todo concepto genérico general es una cualidad existente subjetivamente en el espíritu, que es, por su naturaleza situada fuera del alma, lo mismo que la palabra es un signo de la cosa, que inventa libremente quien la bautiza."16

Una vez comprobadas las raíces nominalistas de la acción productiva del intelecto, volvamos a Hegel, y tratemos de acotar en su obra el tratamiento del intelecto. Decíamos que la inteligencia es comenzada a tratar sistemáticamente por Hegel, cuando el espíritu se sabe determinado por un contenido que intuye como propio, aunque aparece como particular, múltiple y exterior. Pues bien, Hegel acota por arriba la tematización del intelecto cuando:

"La inteligencia sabiéndose a sí misma como determinante del contenido, que tanto es suyo como está determinado como lo que está-siendo, es voluntad.”17

Hegel está negando la separación de facultades. Intelecto y voluntad no se distinguen como dos principios de operaciones anímicos distintos. El intelecto es la actividad que pone como propio lo encontrado. Es decir, el espíritu es intelecto en tanto que se apropia o asimila cognoscitivamente lo externo. Es voluntad en tanto se sabe como lo determinante, lo ponente. La inteligencia subjetiviza la objetividad. La asimila a su propia índole, y al hacerlo conoce la identidad de lo objetivo con lo subjetivo. La actividad del intelecto es libre, pero meramente formal. Para realizar esta libertad, precisa de la voluntad. La voluntad objetiviza la subjetividad, es decir la realiza en un mundo cultural, jurídico, etc. Esta realización de sí es al mismo tiempo una manifestación de sí-Sichselbstoffenbarung-. De aquí que la culminación del tratamiento de la inteligencia sean sus primeras exteriorizaciones: la significación simbólica y la lingüística.

Hemos enmarcado sistemáticamente el estudio hegeliano de la inteligencia. Ahora hay que tratar de su lugar, no en el conjunto del sistema, sino

[15] Cfr.: Inglis, J., Spheres of Philosophical Inquiry and the Historiography of Medieval Philosophy, Brill, Leiden, 1988, p. 51

[16] Hegel, G.W.F., Vorlessungen über die Geschichte der Philosophie, vol. II, en Werke, Moldenhauer, E., y Micel, K., (eds.), Suhrkamp, Frankfurt, 1971, vol XIX, pp. 576-77. Traducción de Roces, W., en FCE, México, 1977, p. 143.

[17] Enz., §468.

THÉMATA. Revista de Filosofía, Nº50 julio-diciembre (2014) pp.: 177-199

doi: 10.12795/themata.2014.i50.08 
en la realidad. Hemos visto que la inteligencia abarca el arco de actividades interiorizantes o asimilantes de lo encontrado por el espíritu. Lo primero que hay que decir, pues, es que al tratar de la inteligencia, Hegel trata del espíritu, y no del alma o de la conciencia. ${ }^{18}$

El espíritu existencialmente es actividad, pura actividad -reine Tätigkeit-, por la que el espíritu se realiza o se produce y crea a sí mismo. Actividad genuina, en sí y dirigida a sí. Y es que Hegel no piensa que el espíritu sea algo al estilo de la sustancia, como una cosa ya terminada y completa. Como si el espíritu fuese un supuesto del que se predican unas acciones, y estas tuviesen un carácter de actos segundos respecto de su propio ser. El espíritu es esencialmente actividad Y la actividad del espíritu se desarrolla como inteligencia y como voluntad.

La inteligencia es este movimiento de producción o de asimilación a la forma racional de lo que el espíritu encuentra ahí, en el mundo o en sí mismo. Por ello, la inteligencia no es pensada por Hegel como una facultad, que pudiera estar en conexión con otras como la sensibilidad o la imaginación. Más bien, al revés: la intuición, la imaginación y el pensar son los tres momentos principales por los que el espíritu se produce teóricamente a sí mismo -Sichselbsthervorbringende-.

Pues bien, y a modo de recapitulación, si el espíritu es actividad, el intelecto es su actividad interna, -innern Tätigkeit des Geistes-interiorizante y subjetivizante, mientras que la voluntad sería su actividad objetivizante. Este acercamiento a la realidad del intelecto, lo diferencia de la conciencia. Pues mientras que en la actividad consciente nos relacionamos con algo otro, externo, en el inteligir, el espíritu sólo se las ha consigo mismo. Actividad, y actividad interna. Esto es lo propio del intelecto, su esencia. Actividad frente a receptividad, que es lo que definitorio de la conciencia, según Hegel. Por eso es preciso advertir cómo emerge la actividad del espíritu de la receptividad consciente.

\section{El primer momento de la inteligencia: la intuición}

Hemos comentado que Hegel niega la separación de facultades. Intelecto y voluntad no son dos facultades separadas, autosuficientes, aunque comunicadas de algún modo. Son dos momentos en la actividad libre del espíritu: el

[18] En esto coinciden tanto Polo como Hegel: el intelecto es espíritu. Coinciden también en la unidad del espíritu, y su no desmembración en facultades. No obstante, para Polo al intelecto se accede como a una realidad que es además de la objetividad. En cambio, Hegel trata del intelecto como comprometido con la objetivación: ya sea en la intuición, en la representación o en el pensar universal y objetivo. En este sentido, el tratamiento hegeliano del intelecto es más afín al kantiano que al poliano. Pues éste reabre una temática muy poco transitada en la historia de la filosofía: las dimensiones inobjetivas del saber

THÉMATA. Revista de Filosofía, N50 julio-diciembre (2014) pp.: 177-199 doi: 10.12795/themata.2014.i50.08 
de idealización y el de manifestación de sí. Una actividad que no es accidental para el espíritu, sino en la que consiste su realización.

Y esta realización del espíritu comienza ya en la sensibilidad. La renuncia de Hegel a distinguir facultades tiene su raíz en que para él el espíritu es intrínsecamente actividad. Pues bien, la negación de la separación de facultades se extiende también hacia abajo. El intelecto no se encuentra ni separado ni en oposición a la sensibilidad como había señalado Kant. La inteligencia es un nivel diferente al de la conciencia. En la conciencia rige la oposición entre sujeto y objeto, mientras que en la inteligencia nos encontramos con la superación de esta oposición por la actividad del intelecto. Para la conciencia, y para filosofías de la conciencia como las de Kant, Reinhold o Fichte, la sensibilidad se opone al entendimiento como una facultad meramente receptiva y pasiva se opone a una facultad espontánea. Y los objetos de la sensibilidad se oponen a los del entendimiento como lo múltiple-mannigfaltig-, exterior y contingente frente a lo universal y necesario. Además la filosofía crítica había sentenciado en su tribunal la ceguera de la intuición. Ceguera que deriva de que la intuición es tan sólo la materia del conocimiento. Aquello que debe ser elaborado y subsumido bajo ciertas estructuras formales para ser conocido.

Frente a la postura de las filosofías de la conciencia, Hegel afirma rotundamente que la actividad intelectiva comienza en la intuición. La intuición no es un tramo cognoscitivo ciego, porque no puede haber momentos ciegos en el conocimiento. Aquí Hegel está siguiendo de cerca de Aristóteles y su caracterización de la actividad intelectiva. Para el estagirita el conocimiento es praxis teleia, actividad que siempre ha alcanzado su fin al ejercerse, una actividad posesora de fin. Pues bien, la postura hegeliana no es una mera rehabilitación de Aristóteles en el mundo moderno. Es ante todo, un enfrentamiento con el nominalismo. Pues es Ockham el que introduce la idea de la ceguera del conocimiento intuitivo. Tesis rechazada toto coelo por Hegel.

Según Ockham el conocimiento del singular es intuitivo. Un contacto real e individual, mediado por los sentidos con una realidad que puede ser localizada numérica y espacio-temporalmente. Dicho contacto es tan singular como el singular intuido. Es decir, es un hecho psíquico frente a un hecho real. Un hecho en el psiquismo que se corresponde mentalmente con el singular. Como ha mostrado de Vries el contacto psíquico con el singular no puede ser cognoscitivo en modo alguno. "Su singularidad, su carácter de estar aquí y ahora, es lo que la certeza sensible toma como lo crucial en los objetos de nuestra experiencia, y correlativamente, toma el conocimiento como presencia directa o relación. Pero esta es una noción completamente inadecuada de lo que es la esencia de un objeto de nuestra experiencia, pues si el objeto se agotase por su presencia ante nosotros, no sería distinto de su experiencia. [...] la experiencia inmediata no distingue el mismo objeto 
dos veces; es imposible para la certeza sensible identificar objetos a través de experiencias." 19

Así el corresponderse intuitivo con el singular no es una adecuación, sino ser el correlato en el psiquismo de lo acontecido extramentalmente. Es un encuentro psíquico con lo otro que el psiquismo o que la subjetividad. Y por lo tanto, en tanto toca lo otro, la intuición está pensada por Ockham siguiendo un modelo voluntario, puesto que la intencionalidad de la voluntad es de alteridad. La intuición del singular no implica una semejanza intencional con él, sino un contacto, una conexión, o una aproximación a lo otro, a otro individuo, a un singular.

Para Ockham, intuición y conocimiento conceptual se oponen. El conocimiento conceptual no trata nunca del singular en cuanto que singular. Si lo aborda de algún modo no es como singular, sino suponiéndolo, como una ficción sobre el hecho intuido. Por su parte, la intuición es el correlato de un encuentro singular con el singular. Encuentro que es ciego, y al que nuestras ideas no refieren, sino que suponen. Es así como la intuición supone lo real, y eso significa que lo determina como fáctico o particular, mientras que las ideas quedan confinadas y aisladas en un orbe interior, subjetivo y autorreferente, pues no son sino hipótesis sobre lo fáctico intuido, sobre lo particular dado y exterior.

Sucede que esta primera mirada del espíritu, este primer ejercicio intelectivo es, para Hegel, un hallar inmediato y abstracto. Se trata de un determinar numérico - un individualizar-, y localizar en el espacio y en el tiempo -loco et numero-, y esto significa, en una distensión indiferente a lo localizado y en una sucesividad indiferente a lo que en su sucederse aparece y desaparece. El espacio y el tiempo no son tanto las formas a priori de la intuición, como lo subsiguiente a la alienación de la Idea absoluta. Pura exterioridad a sí, pura proliferación contingente de singulares.

"La inteligencia determina así el contenido de la sensación como un ente fuera de ella, lo arroja fuera en el espacio y en el tiempo que son las formas en las cuales la inteligencia es intuitiva." ${ }^{20}$

Hegel está aceptando la caracterización nominalista de la naturaleza. Y aparentemente también la caracterización del conocimiento intuitivo como algo refractario al conocimiento de esencias, pues los singulares sólo se dejan relacionar externamente, y la esencia se discierne de lo contingente y exterior. Y desde luego estas contingencias no explican lo que el objeto es en sí, interior o sustancialmente. Pero es en esta exterioridad espacio-temporal en la que según Hegel se realizará el universal.

[19] Vries, W., "Hegel on Reference and Knowledge" en Journal of the History of Philosophy, 26/2, 1988, p. 299.

[20] Enz., § 448 .

THÉMATA. Revista de Filosofía, Nº50 julio-diciembre (2014) pp.: 177-199 doi: 10.12795/themata.2014.i50.08 
Pues bien, Hegel rompe desde el inicio con el planteamiento nominalista. Y su refutación, como a él le gustaba, aprovecha la fuerza del oponente. Y esto significa que a los ojos de Hegel, en el planteamiento de Ockham hay algo verdadero, algo con fuerza y vigor, pero que desde un punto de vista más elevado se puede apreciar como parcial. Y en su parcialidad radica su falsedad. Es decir, según Hegel una crítica es filosófica cuando incluye lo refutado en un punto de vista desde el que se aprecia su limitación o insuficiencia.

Pues bien, Hegel no acepta que la intuición sea ciega porque la intuición es del sujeto. Es decir es suya, del espíritu. Y esto implica que en la intuición hay una actividad espiritual idealizante y referida a lo dado, a lo encontrado. Ockham argüiría que sí, que está de acuerdo, que esa actividad del espíritu corresponde a la voluntad, no al intelecto. Y en esto está de acuerdo Hegel. La actividad que el espíritu pone es voluntaria, y a juicio de Hegel, es la atención — die Aufmerksamkeit-.

"En la disyunción de este hallar inmediato, el primer momento es aquella dirección idéntica y abstracta del espíritu [que se da] tanto en el sentimiento como en las ulteriores determinaciones suyas, la atención, sin la cual nada es para él; es el recuerdo activo, el momento de lo suyo, pero como autodeterminación todavía formal de la inteligencia." ${ }^{1}$

Frente a la alienación de la Idea en el espacio y el tiempo que da lugar a la proliferación irreductible a unidad de lo singular, a una multiplicidad de singulares que sólo cabe relacionar externamente en la forma de leyes generales, Hegel hablará de la atención. La alienación era la intuición de la Idea. La atención es el primer momento de recuperación, de vuelta, de la Idea a sí. Es el momento de la "liberación de la forma de la accidentalidad, singularidad y exterioridad", como se dice en el añadido al parágrafo $441 .^{22}$ La atención permite no sólo el primer contacto con la exterioridad (de eso ya se encargaba la intuición), con el mundo caracterizado en términos nominalistas, sino que la atención es el momento en el que destella la racionalidad, la espiritualidad. Un primer momento de hacer suyo, de reconocer en lo otro, en lo exterior, una racionalidad pareja a la propia del espíritu.

"Sin la atención nada es para el espíritu". Es el primer momento de su actividad, por el cuál él aísla, limita o circunscribe un tema en el flujo múltiple, e irreductible a unidad, de lo que se le da sensiblemente. La atención es la actividad presentificante del espíritu, aquella actividad abstracta y constante -idéntica- que se da para que se pueda objetivar. En este sentido es la primera autodeterminación de la inteligencia. Pero no es una actividad intelectual, sino que como indicó el viejo Ockham, es una actividad voluntaria. Lo que sucede es que Ockham no contemplaba la indisolubilidad entre el intelecto y la voluntad. Y por ello pensó que la intuición del singular sólo

[21] Enz., § 448.

[22] Enz., § 441. Zustaz.

THÉMATA. Revista de Filosofía, №50 julio-diciembre (2014) pp.: 177-199 doi: 10.12795/themata.2014.i50.08 
se correspondía con un hecho fáctico, del que sólo se podían hacer conjeturas desde las ideas fingidas o urdidas por el intelecto.

Pues bien, si no se admite esta separación entre las dos facultades, entonces cabe afirmar que la atención es la actividad voluntaria por la que el ser humano suspende cualquier interés que no sea el cognoscitivo, y merced a ello puede centrarse o permitir a la inteligencia estar inmersa en un contenido dado. Este contenido es lo que deviene temático para el intelecto. Y la actividad voluntaria es lo que permite que el sujeto se lo apropie. "Sin atención nada es para el espíritu". La atención es la actividad apropiante, la inicial toma de posesión de un contenido. Un contenido que el espíritu se da a sí mismo, al fijarse, al retener en el flujo múltiple y heterogéneo de lo dado. Lo retenido es la mirada rememorante del espíritu, la mirada interiorizadora del intelecto. Y por ello, la intuición no puede ser ciega, sino constituyente de los temas.

\section{La inteligencia como imaginación ${ }^{23}$ : el poder creador del espíritu humano}

La actividad intelectiva se inicia con la atención que retiene y tematiza. Sin esta actividad, la inteligencia sería incapaz de apropiarse lo externo, lo existente fáctica y singularmente. Pero este hacer suyo, este interiorizar lo existente exteriormente, implica que la inteligencia ha de retener o guardar la intuición. Se trata del momento de la imagen, de la representación, que según Hegel es el momento de la "intuición recordada" - erinnerte Anschauung- ${ }^{24} \mathrm{He}-$ gel trae a colación la etimología de recordar, que en alemán se dice er-innern, es decir: depositar en el interior, ir hacia dentro de sí -Insichgehen-.

Se trata de un momento capital, central para la inteligencia. Central porque es "el término medio entre el inmediato encontrarse-determinado de la inteligencia y ella misma en su libertad, o sea, el pensamiento". ${ }^{25}$ Este es su lugar sistemático, intermedio entre el puro pensamiento especulativo y la intuición de lo externo y singular. Tan central es este momento de la inteligencia, que Hegel, en las lecciones del semestre de invierno de 1827/28, dirá que "es la síntesis de los dos"26. Síntesis en la que la universalidad del pensamiento

[23] La expresión "Intelligenz als Bildungskraft" es de J. E. Erdmann, y describe muy ajustadamente el segundo momento de realización de la inteligencia, que trata de la representación. Aunque la imaginación es a su vez uno de los momentos de la representación —Vorstellung—, sin embargo cabe denominar genéricamente como imaginación a toda actividad que trata con imágenes, ya sea esta actividad la interiorización, la fantasía o la memoria. Cfr.: Fetscher, I., Hegels Lehre vom Menschen. Kommentar zu den $\$ \S 387$ bis 482 der Enzyklopädie der Philosophischen Wissenschaften, Froomann, Stuttgart-Bad Cannstatt, 1970, p. 156.

[24] Enz., § 451.

[25] Ídem.

[26] Hegel, G. W. F., Vorlesungen über die Philosophie des Geistes. Berlin 1827/28, Franz Hespe y Burkhardt Tuschling, (eds.,) transcritas por Johann Eduard Erdmann y Ferdinand Walter.(Ed.) Vorlesungen. Ausgewählte Nachschriften und Manuskripte, vol. 13, Meiner, Hamburgo, 1994, p. 195.

THÉMATA. Revista de Filosofía, №50 julio-diciembre (2014) pp.: 177-199 doi: 10.12795/themata.2014.i50.08 


\section{El tratamiento hegeliano de la intelección como refutación de la teoria del conocimiento nominalista}

aparece en lo intuido; éste ya no es externo sino propio del espíritu. Pero aún así, su contenido es dado al espíritu. No lo ha producido aún él. Y por ello su libertad es meramente formal.

Es, decíamos, un momento clave. En palabras de Iring Fetscher es el momento en que "lo material se hace espiritual, lo rígido [o entumecido] y muerto, se hace viviente" ${ }^{27}$, un proceso en el que "los materiales encontrados previamente se transforman en algo puramente espiritual, lleno de sentido y viviente" ${ }^{28}$. Se trata de la primera negación del ser natural, aquel ser que es fruto de la alienación de la Idea absoluta, de su mirada fuera de sí, al espacio y al tiempo. Un ser que a juicio de Hegel no sólo se encuentra en la exterioridad, sino que es indiferente a encontrarse aquí o allí, en éste o aquél momento, y que Hegel a veces denomina "ser muerto" 29 . Se trata del singular nominalista. Esto es lo primero negado o suprimido cuando se interioriza una intuición.

Quizá un ejemplo pueda ayudar a comprender por qué Hegel califica al singular nominalista como "ser muerto" . En la película Blade Runner de Ridley Scott, se expresa lo que significa para un ser humano aceptar su muerte. Lo que significa la destrucción de aquel sujeto en el que están interiorizadas "cosas que vosotros no creeríais..., naves de ataque ardiendo más allá de Orión. He visto rayos-C brillar en la oscuridad, cerca de la puerta de Tannhäuser." Todo eso es sentido para la vida, la historia y el cosmos. Todo eso está salvado en la subjetividad de Roy Batty, y él sabe que su muerte implicará que "todos esos momentos se perderán... en el tiempo... como lágrimas en la lluvia." No sólo morirá él, con él también dejará de existir ese sentido, esas verdades del cosmos, de la historia, de la experiencia humana. Ese tiempo en el que se pierde la verdad, y del que habla Roy, es el tiempo alienado, de lo que está fuera de sí; fuera de su lugar propio que es la interioridad humana.

Pues bien, con la interiorización de lo externo, la inteligencia también se intuye a sí, en un primer momento en el que aparece para sí como actividad y mundo interior. Es la primera aparición para sí de la subjetividad, como había señalado ya Ockham y elogia Hegel (v. supra). Se trata de un sujeto, una interioridad y un interior que son en y para sí gracias a la actividad creadora de la imaginación. Creadora en primer lugar de un espacio y un tiempo propios, no naturales, sino espirituales, y en segundo lugar, y concomitante a esta creación, de una interioridad dilatada, vasta y extensa.

[27] Fetscher, I., Hegels Lehre vom Menschen..., p. 158.

[28] Ídem.

[29] "das Tote, weil es sich nicth bewegt, kommt nicht zu Unterschieden des Wesens, nicht zur wesentlichen Entgegensetzung oder Ungleichheit, daher nicht zum Übergange des Entgegenseten in das Entgegengesetzte, nicht zur qualitativen, immanenten, nicht zur Selbstbewegung." Hegel, G.W.F., Phä, SW 3/45.

THÉMATA. Revista de Filosofía, №50 julio-diciembre (2014) pp.: 177-199 doi: 10.12795/themata.2014.i50.08 


\subsection{El tiempo de la inteligencia y la subjetividad}

La intuición es el encuentro con el espacio y el tiempo en el que se localiza este qué singular. En la interiorización se prescinde del este singular, no del qué. El qué es el contenido tanto de la intuición como de la representación. Es lo que queda inalterado a pesar del cambio de forma. El contenido permanece inalterado, más aún, liberado de la forma inmediata y accidental de darse. Hegel está pensando la interiorización de un modo afín al proceso metabólico: hay una eliminación de la forma natural -katabolé- y una asunción por la forma espiritual, de un contenido que queda liberado y a disposición del sujeto -metabolé-. El qué ahora es en un espacio y un tiempo propios.

Así, la primera actividad de la inteligencia, es un hacer suyo el contenido intuido. Y lo hace suyo mudando el espacio y el tiempo en el que lo singular existente es, por un espacio y tiempo interiores, subjetivos, suyos o propios de la inteligencia y la subjetividad -ihrige-. Aquí aparece un tema capital para la filosofía del espíritu hegeliana. Y es el tránsito del tiempo natural al tiempo antropológico. El espacio y el tiempo intelectuales no son ya algo externo al espíritu, sino un espacio, y sobre todo un tiempo, espiritualizados, en el que lo pasado -la intuición recordada-es.

Pero además este tiempo espiritualizado es un tiempo imperecedero, universal. Al ser interiorizada, la intuición, existe en un tiempo detenido. El flujo temporal que disuelve todas las cosas, queda detenido, y así es como queda conservada la imagen.

"La inteligencia hace imperecedero lo perecedero, hace una momia de lo pasado y lo preserva. Este hecho es, en la inteligencia, imperecedero -unvergänglich-, preservado en el tiempo de la inteligencia. El contenido que fue puesto en un tiempo universal -allgemeine Zeit gesetz-deviene permanente; lo que Mnemosyne no recoge en sí -was die Mnemosyne nicht in sich aufnimmt-, ha pasado o se ha perdido." 30

Se trata de un depositar lo intuido en el fondo de la subjetividad humana. Al hacerlo, la inteligencia arranca -saca o extirpa- a lo intuido del lugar y del tiempo exteriores; lugar y tiempo en el que se relacionaba con otros hechos. Lo arranca -herausgenommen- de lo exterior, para recogerlo en sí -in sich auftnimmt-. El contenido, que prescinde de sus múltiples relaciones con otros singulares, es "separado del tiempo"31 y puesto en una "sosegada [o inalterable] duración"32. Además, al interiorizar el contenido, la inteligencia se abre como un "espacio universal" ${ }^{3}$. Ese espacio universal y esa eternidad en los que el singular es incluido, son tan internos al sujeto, que propiamente lo definen, se identifican con él.

[30] Hegel, G.W.F., Vorlesungen über die Philosophie des Geistes, Berlin 1827/28..., p. 198-99

[31] "Trennung des Inhalts von der Zeit". Ibidem.

[32] "ruhige Dauer". Ibidem.

[33] "die Intelligenz ist das Ansich ihrer Besonderheiten, der allgemeine Raum.” Ibid., p. 200.

THÉMATA. Revista de Filosofía, Nº50 julio-diciembre (2014) pp.: 177-199

doi: 10.12795/themata.2014.i50.08 


\title{
El tratamiento hegeliano de la intelección como refutación de la teoria del conocimiento nominalista
}

\begin{abstract}
"La imagen es de suyo fugaz y la inteligencia como atención es su tiempo y también su espacio, su cuándo y su dónde. Pero la inteligencia no es solamente la conciencia y existencia de sus propias determinaciones, sino que como tal es el sujeto y el en-sí de sus determinaciones; recordada en ella, la imagen que ya no está existiendo, está conservada inconscientemente." 34
\end{abstract}

El espacio universal es la intimidad humana que acoge lo externo. Este acoger es un amparar lo verdadero y esencial en la duración inalterable de la inteligencia. Allí queda custodiado. Este contenido se deposita, se sedimenta y asienta en el sujeto. Ahí es, él es su en sí. Ya no es en el espacio y el tiempo físicos, sino separado del tiempo, en una duración inalterable, y en un ámbito que puede acogerlo todo, que puede ser todas las cosas, y en él que todas pueden estar en su verdad.

Interiorizar, recordar, significa pues desprenderse de la alienación, del desperdigamiento en lo muerto y mortífero. Pues bien, para Hegel, aquí, en la interioridad humana las cosas son más de verdad que en su accidentalidad empírica. Que se den de hecho, empírica, particular y singularmente, no significa que se den en su racionalidad, en su equivalencia inteligible. Son, como son en su esencia, en su universalidad. Y esto se logra en la intimidad humana, que extrae, saca a lo ideal de su extravío.

La actividad intelectiva, según Hegel implica "una suspensión del flujo temporal y un pasado intemporal uniforme que, de forma comparable a la Esencia en la Lógica, es un haber sido intemporal". ${ }^{35}$ El contenido liberado de sus determinaciones espacio-temporales es lo que es en cualquier tiempo, en todo el tiempo. Es lo que siempre es. La interioridad humana transmuta en eternidad todo lo efímero, accidental y contingente. Más que un mudar es un incluirlo en la sustancia del yo. Y esto lo realiza el espíritu que como actividad pura, es la fuerza redentora de la vanidad del tiempo.

Hegel denomina a esta apropiación "idealización”. La idealización implica la negación o eliminación de los elementos empíricos o fácticos de la intuición. Pero no habría idealización si el contenido no fuera preservado como un momento en la inteligencia, en el yo. Así, el ser ideal - das Ideelle- es el intuido pero no como independiente, sino como un momento en la inteligencia. Ese era el significado que tenía lo ideal como inclusión de lo finito en el verdadero infinito en la Ciencia de la Lógica. Y "la característica definitoria de un momento, según el punto de vista de Hegel, es no tener una identidad separada, sino logar su carácter del papel que juega dentro de un todo al que ayuda a constituir." ${ }^{36}$ La representación es en el yo, constituyendo la intimidad subjetiva, no separándose de ella, sino constituyéndola, definiéndola. Y así como en la

[34] Enz., § 453.

[35] Ibid., p. 297.

[36] Williams, R., Tragedy, Recognition and the Death of God, Oxford University Press, Oxford, 2012, p. 172.

THÉMATA. Revista de Filosofía, №50 julio-diciembre (2014) pp.: 177-199

doi: 10.12795/themata.2014.i50.08 
Ciencia de la Lógica, Hegel sostuvo que la verdad de lo finito es su idealización, ahora también mantiene que la verdad de lo intuido es lograda merced a su interiorización, a su idealización.

Aquí aparece una curiosa interpretación de la praxis teleia aristotélica. Y es que lo definitorio de la acción cognoscitiva, según Aristóteles, estriba en que alcanza su fin al ejercerse: se piensa y ya se ha pensado. Siempre se piensa en un tiempo pretérito perfecto. La acción ya ha logrado el objeto conocido al pensar. Y por eso Aristóteles dice que la actividad intelectiva posee objeto. Lo posee en su ejercicio. Es propiamente una actividad posesora.

Cuando Hegel explique la relación entre la intuición y el universal, señalará que cuando pensamos un particular, subsumimos su intuición bajo el contenido sedimentado en la inteligencia, lo subsumimos como lo particular bajo lo universal, y aplicamos lo ya sabido, lo que yacía en el abismo tranquilo de la conciencia a lo ahora presente.

“Aplico mi imagen a lo presente. Entonces digo: 'yo he visto esto'. Esto significa que lo que es pasado en la inteligencia, es ahora presente -Vergangenheit in der Intelligenz, das ist Gegenwart-. 'Tener' significa aquí lo que 'tener' significa realmente, es decir, poseer. Yo lo tengo como algo visto; es algo que ha sucedido y yo lo poseo." 37

Hegel no se cansa de enfatizar que la inteligencia es pura actividad poseedora, habiente. Es preciso no separar el momento de actividad del momento de posesión. Tanto para Aristóteles como para Hegel son inseparables. Conocer como acto es poseer. Pero para Hegel esto significa que "la inteligencia es activa en la imagen y en posesión de ella. -Die Intelligenz tätig in Bild, in desem Besitz-. Éste es el momento de la imaginación." ${ }^{38}$ Según Aristóteles, la actividad intelectual consiste en la presentación del objeto. Según Hegel en urdir, tramar, efectuar sobre lo sedimentado en ella. Y al hacerlo, establecer conexiones, relaciones en el rico patrimonio de imágenes interiorizadas cabe ella, en sus honduras. ${ }^{39}$

\subsection{El abismo de la conciencia}

Hegel siempre presenta la intuición como un mirar-fuera. En la Ciencia de la Lógica, la Idea absoluta mira fuera de sí, y entonces se aliena en lo singular espacio-temporal. La exterioridad es precisamente la exterioridad a la

[37] Ibid., p. 200-01.

[38] Ibid., p. 202.

[39] Según Leonardo Polo, la primera actividad intelectual, la abstracción consiste precisamente en artícular las imágenes de la fantasía con las intenciones de pasado y futuro proporcionadas por la memoria y la cogitativa. Compárese esta tesis con la hegeliana: "La inteligencia mantiene estas imágenes juntas, es la unidad, el sujeto, la conexión, la relación, en la que tienen su subsistencia esta multiplicidad de imágenes. Es su vínculo. Su evocación es conectiva, deviene objetiva como el elemento que conecta en esta evocación." Hegel, G.W.F., Vorlesungen über die Philosophie des Geistes, Berlin 1827/28..., p. 202.

THÉMATA. Revista de Filosofía, N50 julio-diciembre (2014) pp.: 177-199 doi: 10.12795/themata.2014.i50.08 
Idea absoluta. Del mismo modo, hemos visto que en la filosofía del espíritu subjetivo, el ser humano mira fuera cuando intuye. Y entonces se encuentra con lo particular. También la Idea absoluta se encuentra con lo particular, pero en este caso, porque lo genera, porque se aliena a sí dando lugar a ellos. El espíritu finito, en cambio, se encuentra con lo particular, tropieza con lo fáctico, pero no lo genera, sino que es como determinado por ello. Estar cabe sí, cabe uno, comenzar a salir de la alienación, es lo que acontece al pensar, al interiorizar. Ahí nos encontramos con lo universal, y con ello rescatamos lo verdadero y esencial de su extravío en el tiempo, de su disolverse como lágrimas en la lluvia...

El recuerdo en sentido hegeliano es una interiorización, no un recuerdo efectivamente consciente. No se trata de la interiorización de un hecho, de lo por ejemplo acontecido en tal momento y en tal lugar. La imagen es en la interioridad, siendo lo definitorio de tal interioridad subjetiva el mundo de imágenes en el que el sujeto vive, y del que se nutre espiritualmente. Pues bien, el contenido de la intuición, liberado ya de sus particularidades fácticas, "queda sepultado en el abismo de mi conciencia" 40 .

Recuérdese que la inteligencia se diferencia de la conciencia. Ésta última se relaciona con lo externo. La inteligencia en cambio es una actividad en la que el espíritu se encuentra a solas consigo mismo. Por lo tanto, que el contenido sea interiorizado, sea mío, significa subsumirlo bajo el yo. Esta apropiación del contenido no implica que el yo sea consciente de lo subsumido en él, sino que lo intuido está incluido en la unidad de mi yo.

Hegel habla de la muerte, de un contenido sepultado, enterrado -vergraben- en la noche, en el fondo de la conciencia. Y habla también del ser muerto, los hechos empíricos. Parece como si la redención de la verdad, de lo esencial, implicara su sepultura en la noche del yo. Sólo ahí podrá revivir la Idea, resurgir como un ave fénix de las cenizas en que se perdió alienándose. El intelecto no es para Hegel sólo luz. Es también un abismo nocturno de imágenes. Es preciso:

"Comprender la inteligencia en tanto es este pozo oscuro en el que se guarda un mundo infinito de numerosas imágenes y representaciones, sin que estén en la conciencia..." ${ }^{41}$

Interiorizar la representación, no es sino poner su contenido en la subjetividad humana. Establezco con lo exterior una relación subjetiva. ${ }^{42}$ Pero que esta relación sea subjetiva no implica que carezca de verdad, porque lo interiorizado "tiene el mismo contenido que la intuición. Mi representación está puesta así como verdadera, está confirmada"43.

[40] "Das Bild im Schacht meines Bewußtseins vergraben" Hegel, G.W.F., Vorlesungen über die Philosophie des Geistes, Berlin 1827/28..., p. 200.

[41] Ídem.

[42] Hegel, G.W.F., Vorlesungen über die Philosophie des Geistes, Berlin 1827/28..., p. 197.

[43] Ibid., p. 201.

THÉMATA. Revista de Filosofía, $\mathrm{N}^{\circ} 50$ julio-diciembre (2014) pp.: 177-199

doi: 10.12795/themata.2014.i50.08 
Aquí nos encontramos con una importante tesis sobre la actividad intelectiva: el recuerdo de la intuición asume todo su contenido, sin residuo ninguno. El contenido de la representación es idéntico al de la intuición. Sólo varía su forma, que en la representación es la de la universalidad e interioridad, y en la intuición es la de la exterioridad y singularidad. La forma del contenido es pues, en la representación, la de su pertenencia a la inteligencia, y por lo tanto, la que tiene porque las representaciones me pertenecen. Por eso, el contenido es depositado en la noche del espíritu. Exteriormente estaba muerto, y la inteligencia lo acoge en su seno, le da su sepultura, esperando el momento de revivirlo, de ser su nueva alma.

Se trata de una tesis antinominalista porque lo intuido y lo forjado por la mente no se distinguen radicalmente, sino que se identifican. ${ }^{44}$ Para un nominalista el contenido empírico intuido se diferenciaba absolutamente de lo formado o urdido por la mente. En lo mental se confinaba la posibilidad mental, es decir, lo que podía corresponderse o no con lo singular intuido. Lo posible y lo empírico se distinguen, a juicio de Ockham, como dos mundos absolutamente diversos y estancos. Si es empírico no es mental. Si es posible, entonces no se da exterior y singularmente.

Hegel acepta esta separación. Pero como una separación formal. En este pozo oscuro las imágenes son. El yo es el lugar de lo interiorizado, el topos tôn eidôn, como habría dicho Aristóteles, pero en este momento como algo en sí. La subjetividad es su en. Ellas no son aún para el sujeto. Pero éste las acoge no como un mero habitáculo receptivo, sino activamente.

Siguiendo a los escotistas, Hegel habla de la representación, de lo interiorizado e incluido en la unidad del yo, como una "posibilidad virtual." 45 No de una potencia impotente, y necesitada de un auxilio externo que la pase al acto, sino como fuerza, callada y oculta pero activa. Este es el momento en que el ser muerto, revive, como reanimado por el yo. El momento en que lo sepultado en la noche del espíritu "es fuerza y actividad que precontiene el acto virtualmente (virtus $=$ fuerza) y se lo confiere a sí misma" ${ }^{46}$.

"El contenido es asumido por el sujeto; el alma particular de este contenido muere -ist getötet-, y la inteligencia es su alma -die Intelligenz ist seine Seele-. Esto implica que el sujeto es el fundamento que soporta y vincula el contenido." ${ }^{47}$

[44] Este es uno de los puntos principales de disenso de Leonardo Polo para con Hegel. A juicio de Polo, las ideas generales versan sobre las nociones de las que tenemos conciencia inmediata de modo que no asumen íntegramente su contenido, sino que lo particularizan. Lo dado inmediatamente a la conciencia, es a juicio de Polo, lo vasto. Un rico contenido del que se prescinde casi en su totalidad por la idea general, que rige sólo sobre una nota de cada abstracto. A juicio pues de Polo, la noción de singular, individuo o caso, es lógica, y no extramental. Es así como Polo rechaza $a b$ initio el planteamiento nominalista y empirista. El singular no es real, sino lógico. Una extrapolación debida al límite de la inteligencia.

[45] Enz., § 453.

[46] Valls, R., nota 770 en Hegel, G.W.F., Enciclopedia...., p. 495.

[47] "dieser Inhalt wird getragen vom Subjekt, die eigene Seele dieses Inhalts ist getötet, und die Intelligenz ist seine Seele. Darin liegt, da $\beta$ Subjket das tragende und verknüpfende Band dieses

THÉMATA. Revista de Filosofía, №50 julio-diciembre (2014) pp.: 177-199

doi: 10.12795/themata.2014.i50.08 
Esta vida del intelecto en su mundo interiorizado se manifiesta de múltiples maneras. Hegel en sus lecciones pone una dieta muy rica de ejemplos. Por ejemplo los chistes, las bromas, los juegos de palabras, los retruécanos. "Una agudeza inteligente trae a colación lo que es remoto, pero que está esencial e inherentemente conectado." ${ }^{48}$ En modo alguno el fenómeno del chiste se podría explicar con las leyes empiristas de asociación de ideas. Esas asociaciones de las que hablaban Locke, Hume, Hissman o Bardili. Para urdir y para comprender un buen chiste se necesita de un yo rápido, ingenioso, agudo, Por eso, una mente que sólo conecta superficialmente, también hace flojo y malo el chiste. ${ }^{49}$

Otro fenómeno en el que se aprecia como el yo hace revivir lo que está sedimentado en el fondo de su conciencia son "las pasiones, los intereses más profundos, que son elementos esenciales en esta conexión. Una persona consumida por una pasión tan sólo encuentra referencias a su pasión en cualquier cosa y cualquier lugar." ${ }^{50}$ También los estados de ánimo hacen que el sujeto conecte entre sí representaciones de un modo u otro. Un yo brillante, alegre y otro sombrío y lúgubre asocian de modo diferente. $\mathrm{Y}$ asocian independientemente de la fuerza atractiva que de suyo tengan las notas noeticas. Es el sujeto esa fuerza atractiva, que por eso puede prescindir o vincular el contenido al margen del modo como el contenido se conectaría de suyo. ${ }^{51}$ Por eso el yo alegre y el lúgubre subrayan lo mejor o lo peor de las cosas y personas con quienes se encuentran.

\subsection{La formación de ideas generales, símbolos y signos}

Lo depositado en la noche interior es una posibilidad virtual para el yo, para su inteligencia. No es algo que actúa mecánicamente, al margen de la subjetividad. Y si actúa, es porque aún el intelecto no ha tomado posesión de ello. Toma de posesión en la que se va manifestando la fuerza y vitalidad del yo. Una energía que es menor en la combinación y asociación de imágenes, y que se acrecienta en la forja de símbolos y signos, en los que el yo se hace independiente de lo dado, y crea con su mundo.

De nuevo aparece una semejanza y una diferencia para con el nominalismo. Lo posible es mental para Hegel y Ockham. Pero para Hegel, esta posibilidad es una verdadera dynamis kata logon, es la fecundación del intelecto, lo inteligible en sí, en la noche oscura del intelecto, en un fondo que aún no ha aparecido conscientemente. Pero no por interiorizado, lo eidético se desarrolla

Inhalt ist." Hegel, G.W.F., Vorlesungen über die Philosophie des Geistes, Berlin 1827/28..., p. 202.

[48] Ibid., p. 204.

[49] Ídem.

[50] Ídem.

[51] "el contenido mismo no se encuentra ya internamente conectado. Más bien, la misma inteligencia es la que lo mantiene unido, y la que puede, igualmente, desligarlo." Ibid., p. 204.

THÉMATA. Revista de Filosofía, №50 julio-diciembre (2014) pp.: 177-199 doi: 10.12795/themata.2014.i50.08 
de suyo. Es posibilidad como lo virtualmente disponible para el intelecto. No es la mera posibilidad de corresponderse o no hipotéticamente con la realidad, sino lo posible como disponible para el yo. El intelecto queda dispuesto -hexisasí para su actividad. ${ }^{52}$

El espíritu es esencialmente actividad. El yo es activo para con las representaciones, para con las posibilidades virtuales del intelecto. El yo teje, compone urde, entrelaza estas posibilidades unas con otras. Y el primer modo de urdir es "atender a una determinación, es la abstracción, o el método de formar representaciones universales". ${ }^{53} \mathrm{La}$ mirada intelectual, la mirada del yo "aísla, destaca -vereinzeln, heraushebt-" ${ }^{54}$ una nota de lo intuido, y concentrada en esa nota busca otras representaciones que la compartan. Es la inteligencia como fuerza conectiva, como imaginación asociativa -zusammenhängende, assoziierende Einbildungskraft- ${ }^{55}$.

Con ello se logra "la disolución y la muerte de la imagen intuida" ${ }^{56}$ Se trata de un momento de libertad y de génesis, de revivir. El primer momento en que la inteligencia genera algo con independencia del contenido dado. "El contenido es tomado de lo dado, pero la forma es la de un analizar, y la determinación es aislada (la unidad concreta es cancelada), es relacionada consigo, y con esto, es hecho abstracto." ${ }^{57}$ Es precisamente lo dado lo que muere, lo que es descompuesto, catabolizado por la inteligencia, que atiende a una única nota de lo dado, y genera una idea general o universal que aglutina en sí todas las imágenes que comparten dicha nota.

Frente al poder gravitatorio que la teoría del conocimiento empirista atribuía a las notas semejantes, cercanas, etc., Hegel subraya por el contrario, "el poder de la inteligencia sobre esta materia, -Die Intelligenz als Einbildungskraft ist die Macht über diesen Stoff-, este material, el almacén de representaciones e imágenes" ${ }^{58}$ Esto es lo que significa haber tomado posesión, tener la imagen. Y frente a la mera posibilidad mental e hipotética del nominalismo, Hegel, también al contrario, subraya que "la imagen es lo inesencial frente al constructo intelectual" 59 . Lo esencial y verdadero es lo urdido, lo producido, lo tramado por la mente, por el yo que asocia representaciones, que se fija en notas, y que logra lo universal.

[52] Cfr.: Ferrarin, A., Hegel and Aristotle, Cambridge University Press, Cambridge, Mass., 2004, p. 290.

[53] Hegel, G.W.F., Vorlesungen über die Philosophie des Geistes, Berlin 1827/28..., p. 204.

[54] Ibid., p. 205.

[55] Ídem.

[56] “die Auflösung, Tötung des Bildes der Anschauung”. Ibidem.

[57] Ídem.

[58] Ídem.

[59] “das Bild [...] das Unwesentliche gegen das Gebilde der Intelligenz.” Ibid., p. 206.

THÉMATA. Revista de Filosofía, Nº50 julio-diciembre (2014) pp.: 177-199 doi: 10.12795/themata.2014.i50.08 


\section{El tratamiento hegeliano de la intelección como refutación de la teoria del conocimiento nominalista}

De nuevo, lo capital es la actividad del yo, la actividad del espíritu. Actividad que comienza a ser libre de lo dado. Y no sólo se concentra en una de sus notas y genera lo universal, disolviendo la unidad dada. También puede "formar y configurar el contenido dado". ${ }^{60}$ La inteligencia entonces produce los símbolos, que dan forma sensible, perceptible, a un universal -verbidlicht das Allgemeiney da una nueva vida, "un nuevo significado y sentido a la imagen". ${ }^{1}$

"Esta unidad es la figuración de lo que es universal y la universalización de la imagen [...] la representación universal no se unifica con la imagen para formar un producto neutral, podría decirse, químico, sino que es activo y se acredita como el poder sustancial sobre la imagen, se la subordina como algo accidental, y se hace su alma, siendo en ella para sí, la interioriza y se manifiesta a sí mismo." ${ }^{2}$

El símbolo viene a ser la animación definitiva del ser muerto y sepultado en el fondo de la conciencia. Ahora su alma, su sentido, es puesto por la inteligencia. Es una idea universal. Aún la libertad del intelecto es formal, no se ha desembarazado de lo dado, de lo intuido. Pero lo ha penetrado, lo ha atravesado por completo. Frente a Kant, el yo no sólo acompaña a cada una de mis representaciones, sino que las configura, la forma, es activo en ellas. Ahora se aprecia mejor la comprensión hegeliana de la praxis telia aristotélica (v. supra 4.1. in fine).

La primera actividad intelectual es la atención, y ésta permite la interiorización, el recuerdo. En este momento, la inteligencia se afirma a sí, y quiere exteriorizarse -Entäusserung-. Se exterioriza en la imagen, y en ella muestra su señorío, su poder. Pero esta exteriorización es aún débil. El intelecto puede darse a sí una existencia inmediata, fáctica, como la que tenía lo intuido. Quiere mostrar su soberanía no sólo respecto de lo interior, sino dar lugar a lo exterior, producirlo. Y esto son los signos, y ante todo los signos lingüísticos: la autoexpresión de la inteligencia en tonos y sonidos, grafos y colores.

Y ahí se observa la toma de posesión intelectual. Lo externo "es una cosa sobre la que la inteligencia viene y usa, o activa su corporeidad para poner algo intuible." ${ }^{3}$ Pero al hacerlo, la inteligencia transmuta lo empírico, lo fáctico singular y exterior. Lo hace renacer, existir de un modo nuevo, más verdadero y más espiritual. Se trata del modo de ser de lo lingüístico, en el que el tiempo mismo es transmutado de espiritualidad: "Las cosas inmediatas adquieren una segunda existencia a través del lenguaje. [...] Esta exis-

[60] "Die Intelligenz bildet sich den vorhandenen gegebenen Stoff an". Ibidem.

[61] Ibid., p. 207.

[62] Enz., § 456 Zusatz. “'Diese Einheit, die Verbildlichung des Allgemeinen und die Verallgemeinerung des Bildes kommt näher dadurch zustande, daß die allgemeine Vorstellung sich nicht zu einem neutralen, sozusagen chemischen Produkte mit dem Bilde vereinigt, sondern sich als die substantielle Macht über das Bild betätigt und bewährt, dasselbe als ein Akzidentelles sich unterwirft, sich zu dessen Seele macht, in ihm für sich wird, sich erinnert, sich selber manifestiert." [63] Hegel, G.W.F., Vorlesungen über die Philosophie des Geistes, Berlin 1827/28..., p. 209.

THÉMATA. Revista de Filosofía, $\mathrm{N}^{\circ} 50$ julio-diciembre (2014) pp.: 177-199 doi: 10.12795/themata.2014.i50.08 
tencia que adquiere la cosa por mí -el nombre- es el renacer del contenido -die Wiedergeburt des Inhalts- desde la inteligencia." ${ }^{64}$

En el símbolo doy forma sensible a un contenido intelectual. La inteligencia asocia un significado a una intuición recordada, interiorizada. En el signo, por el contrario, el enlace es completamente libre. El espíritu demuestra su absoluto carácter creador poniéndose él mismo como alma del signo.

Se trata del poder sustancial del intelecto que puede prescindir incluso de toda referencia a la intuición, que cumple así su liberación respecto del ser empírico. La verdad entonces se fundamenta en sí misma, en la capacidad del intelecto para conservar, para interiorizar. Conservar, guardar, custodiar se dice en alemán "bewahren". Y Hegel vuelve a jugar con el lenguaje al señalar que la interiorización es el momento de la verdad be-wahr (wahr = verdadero). La verdad no refiere fuera, a lo intuido, sino a lo conservado en el intelecto. Eso es lo verdadero, y el fundamento de la verdad. El intelecto es autorreferente.

De nuevo la distancia para con el nominalismo no puede ser mayor. Stat rosa pristina nomine, nomina nuda tenemus... de la rosa primigenia sólo nos queda el nombre, sólo tenemos nombres desnudos, carentes de realidad.... Nada más nominalista que este lema que concluye la famosa novela de Umberto Eco, El nombre de la rosa. Pero también nada más distante de la postura de Hegel, en la que los nombres son la existencia renacida desde el espíritu. Pero por existir ahí, de modo fáctico, "la palabra es particular y transitoria, y la siguiente acción de la inteligencia consiste en que la palabra devenga permanente." ${ }^{65}$ De esto se encarga la inteligencia en cuanto memoria, que conecta permanente y universalmente a la palabra objetiva el significado que ha recibido de la subjetividad. De este modo el nombre es la unidad de lo subjetivo y lo objetivo. Y con ello, la realización plena de lo racional, la toma de posesión por el yo de lo fáctico, del mundo, de lo natural.

En el signo lingüístico el espíritu se exterioriza. Y lo hace en un conjunto de sonidos que al margen de su ser signo-de, carecen de sentido, son arbitrarios. El signo lingüístico es convencional, una producción del espíritu, por el que el contenido intelectual existe, tiene un ser ahí, una existencia temporal. Como exteriorización suya, la inteligencia piensa con palabras, con lo suyo -das Seinige-, con la objetivación de su actividad subjetiva.

No pensamos con imágenes mentales, sino con palabras (Enz. § 462). Hegel quiere hacer notar la afinidad entre la memoria y el pensamiento. Encuentra un parentesco etimológico entre Gedächtniss (memoria) y pensamiento (Gedanke). En la palabra está el contenido, pero independientemente de que tengamos que imaginar tal contenido.

[64] Ibidem.

[65] Ibid., p. 214.

THÉMATA. Revista de Filosofía, Nº50 julio-diciembre (2014) pp.: 177-199 doi: 10.12795/themata.2014.i50.08 
Lo peculiar de las palabras es que su alma es el espíritu. Sólo son en y por la inteligencia. Lo que tienen de objetivo es puesto por la subjetividad. Esto se hace especialmente patente en el fenómeno de la memoria mecánica. Aquí la memoria conecta signos que incluso pueden no tener ningún sentido para el que las reúne, un conjunto de datos aparentemente aislados entre sí, encontrados externamente, y con una conexión contingente entre sí. Mantenerse en esta abstracción y despojamiento de cualquier sentido sólo puede ser logrado por la inteligencia. Ella es el único vínculo posible, la fuerza que conecta. Y no sólo los significados, sino también los meros signos despojados de su referencia. Ésta logra ser y reconocerse como tal, incluso en lo más alejado de sí misma, en un mecanismo. Con esto se logra ver también el poder del espíritu, pues este alcanza tanto como su exposición. Y no sólo el poder del espíritu, sino su relación con la naturaleza, con lo corpóreo, la palabra, el lenguaje, los signos. 
